ISSN 1981-416X

Licenciado sob uma Licença Creative Commons

\title{
Inclusão digital para mulheres em situação de vulnerabilidade social: a percepção dos formadores
}

\section{Digital inclusion for women in situation of social vulnerability: the teachers' perceptions}

\section{Stela Rosa, Roseli Zen Cerny, Marina Bazzo de Espíndola*}

\section{Resumo}

Este artigo se dedica a uma reflexão sobre a inclusão digital, por meio de processos formativos para mulheres em situação de vulnerabilidade social, alvo das políticas sociais de combate à pobreza. Para isso, analisa as percepções de docentes e servidores do Programa Mulheres Mil sobre a relação destas mulheres com a cultura digital. Os resultados apontam que os professores não identificam a existência de relações das mulheres-alvo do programa com as TIDC tampouco como sujeitos da cultura digital, reduzindo a inclusão digital ao repasse instrumental de conteúdos básicos de informática. Discutimos que, mesmo iniciantes no manejo do computador e internet, elas têm familiaridade com outras tecnologias, como o celular, principal instrumento de contato entre as estudantes e os agentes das políticas públicas, além de serem diretamente controladas pelos sistemas de monitoramento das exigências destas políticas ou das organizações de seus trabalhos. Como

"SR: Mestra em Educação, e-mail: stelammrosa@gmail.com RZC: Doutora em Educação, e-mail: rosezencerny@gmail.com MBE: Doutora em Educação, Gestão e Difusão em Biociências, e-mail: marinabazzo@gmail.com 
integrantes da sociedade atual, as mulheres do Programa Mulheres Mil têm o direito a compreender a cultura em que vivem para que possam interagir de forma crítica, sem que sejam apenas usuárias ou consumidoras inconscientes.

Palavras-chave: Cultura Digital. Inclusão Digital. Vulnerabilidade Social.

\begin{abstract}
This article intends to discuss digital inclusion through educative processes for women in situation of social vulnerability. To do so, this study analyses teachers' perceptions about the relationship between these women and digital culture in the context of the Mulheres Mil Program. The results show teachers do not identify any relationship between those women and digital information and communication technologies, understanding digital inclusion for them only as the knowledge required to operate those technologies. We argue that even though they are beginners on the use of computer and internet, they are surrounded by and familiar with other technologies such as mobile phones. Those technologies are the main instrument of communication between them, the public policies' agents and their work management, to control and regulate their lives. Being part of a digital culture, women in situation of social vulnerability need to develop a critical view about DICT, understand the current culture aiming to participate not only as users or unaware consumers.
\end{abstract}

Keywords: Digital Culture. Digital inclusion. Social vulnerability.

\title{
Política pública e tecnologia digital: o controle do corpo e da vida
}

Eu descobri muita coisa interessante, descobri a internet que até então eu não sabia nem como entrar e chegar assim pertinho do computador eu não podia. Tinha até medo de chegar perto, porque disseram que o computador descobria logo tudo da vida da gente. Era só digitar o nome da gente, e realmente, quando a gente digita sai logo tudo (RATTON, 2009). 
Foi incrível! Como eu disse a primeira vez, as meninas até riram lá em casa quando eu falei isso na minha entrevista - eu tinha medo de computador. Realmente, eu não chegava nem perto. Morria de medo. Minha mãe dizia: 'Menina, esse bicho aí é um bicho do outro mundo, é um bicho do final dos tempos porque descobre a vida da gente todinha'. E descobre mesmo! Quer ver? Vamos supor: você está num apartamento, termina de limpar todo e dá o clean. O clean é digitar um código. Aí, aquela supervisora lá embaixo sabe onde você tá, onde entrou. Quando passa a chave no trinco do apartamento, acusa no computador. Todo mundo sabe a que horas você entrou, quantas vezes, o tempo que ficou lá dentro. Então o computador sabe tudo mesmo [risos] (ROSA, 2011b).

Estes depoimentos ilustram a discussão que pretendemos trazer neste artigo, a inclusão digital por meio de processos formativos para mulheres em situação de vulnerabilidade social, alvo das políticas sociais de combate à pobreza. O estudo analisa as percepções de docentes e servidores do Programa Mulheres Mil sobre a relação destas mulheres com a cultura digital, aspectos que estão presentes nas falas de Selma, aluna do curso de camareira, ofertado pelo Instituto Federal do Ceará (IFCE).

Selma, uma das estudantes das regiões pobres do país - Norte e Nordeste, lócus da ação piloto do Programa, teve uma trajetória exemplar - concluiu o curso e se inseriu no mercado de trabalho. Quando iniciou a qualificação profissional, em 2008, aos 43 anos, deparou-se com a disciplina de introdução à informática, momento em que foi desafiada a enfrentar o "bicho-papão" que lhe parecia o computador: algo misterioso que lhe dava medo, como se fosse uma espécie de ressonância magnética, que ia além do que ela parecia conhecer, pois o desnudamento, para Selma, não era só do corpo, mas das intimidades da vida. Em 2010, quando ingressou no sonhado mundo formal do trabalho como camareira em um dos hotéis de luxo de Fortaleza, ratificou e ampliou sua teoria: esses novos artefatos tecnológicos podiam não só saber tudo da vida, mas também disciplinar a rotina laboral: controlar os tempos e espaços de sua circulação no hotel.

Caminhadas como a de Selma influenciam a implantação de políticas que articulam educação, pobreza e gênero que, em 2011, materializam-se na transformação dessa experiência piloto, desenvolvida em parceria entre 
os colleges canadenses e os Institutos Federais (IFs), no Programa Nacional Mulheres Mil, que passou a ser ofertado em todas as regiões do país com a meta de articular educação profissional com elevação de escolaridade, integrando-se assim às políticas de Educação de Jovens e Adultos (EJA). A identificação e reconhecimento dos saberes das experiências de vida é princípio balizador dessa ação educacional tanto para definir o itinerário formativo, ampliando a possibilidade de continuidade dos estudos na instituição, quanto para qualificação profissional. Os cursos deveriam ter no mínimo 160h e um eixo central comum, composto por conteúdos das áreas de linguagem, matemática, ciência e temas transversais, entre eles informática básica e aplicada (BRASIL, 2011a; 2011b).

Inserindo-se nas ações de combate à pobreza, pertencer ao sexo feminino e ser caracterizada em situação de vulnerabilidade social compõem os critérios de acesso ao Programa Dupla que, na perspectiva de gênero, integra-se à ideia de feminização da pobreza, que ganha força nos movimentos feministas, nas conferências da Organização da Nações Unidas (ONU) na década de 1980, e se incorpora aos discursos das agências internacionais enquanto um imperativo para os países da América Latina: implementar políticas públicas para mulheres pobres com filhos, para a pretensa inclusão social, via transferência de renda, e a prevenção da hereditariedade da pobreza (CHANT, 2006). No Brasil, essa tríade é materializada no Programa Bolsa Família, que, ao mesmo tempo que distribui renda, tem como exigência às mulheres, beneficiárias preferenciais, garantir a frequência dos filhos na escola e na unidade de saúde (PINZANI; REGO, 2014).

Se no campo onde se cruzam educação e tecnologia parece ser mais comum articular as concepções de exclusão social e inclusão digital (BONILLA; OLIVEIRA, 2011), compreender os significados da condição de vulnerável social, como são caracterizadas as beneficiárias das políticas de combate à pobreza, é relevante para entender como essa condição é ambígua no que diz respeito à integração e à percepção das relações dessas pessoas na e com a cultura digital, pois se localizam na zona fronteiriça do dentro e do fora: inseridas e excluídas da cultura digital. 
Na política pública, Monteiro (2011) argumenta que o conceito de vulnerabilidade social relaciona-se ao desequilíbrio e à carência, que engloba os ativos, recursos materiais e socioculturais que possibilitam aos indivíduos se desenvolverem na sociedade, tais como trabalho, lazer, cultura e educação; o conjunto de oportunidades procedentes do âmbito social, concedidas pelo mercado, Estado e sociedade; e as estratégias, definidas como as formas por meio das quais os indivíduos usam os ativos para construir mudanças estruturais de um dado contexto social. Mas, se na política pública as noções que circunscrevem as concepções da vulnerabilidade social são carência e marginalidade, na perspectiva de Souza (2009, p. 23-24) trata-se de um fenômeno de naturalização da desigualdade que gera a Ralé, categoria cunhada pelo sociólogo para pensar os que se encontram à margem, os produzidos na sociedade brasileira como subgente: classe social que "sempre foi (in)visível, entre nós, e percebida apenas como 'conjuntos de indivíduos', carentes ou perigosos". São os invisíveis que nas relações cotidianas estão vulneráveis a situações de exploração subempregos e trabalho escravo - , de violência, especialmente contra as mulheres, e de feminicídio, a moradias em áreas de risco, a preconceitos e exclusão social. Isso não significa que esses estejam fora da cultura digital. Ao contrário, estão inseridos de forma subalterna, e as tecnologias digitais são instrumentos de controle e monitoramento nas políticas de combate à pobreza, estabelecendo critérios de acesso, comportamentos, atitudes e instituindo linguagens.

Assim, Selma, a nossa camareira de sucesso, cujo depoimento no vídeo acerca do seu medo da internet arranca da plateia sorrisos de deboche, como se ela, a vulnerável social, falasse algo irreal, parecia intuir, mesmo sem saber da existência do potencial e alcance da ligação em rede de dados para fins de governo, que havia algo na "internet" que sabia muitas coisas da sua vida. E realmente sabia! Selma recebia o Bolsa Família e o Benefício de Prestação Continuada (BPC) para o filho mais velho, que nasceu com paralisia cerebral. Selma, assim como os 50 milhões 
de vulneráveis sociais, parcela da população que vive na linha da pobreza ${ }^{1}$, nas políticas públicas se transformam em NIS, Número de Identificação Social, um registro para o Bolsa Família e outros programas sociais do governo, por meio do qual os beneficiários se submetem às regras do Estado: a liberação do recurso é condicionada ao cumprimento das exigências, envolvendo assim alimentação no sistema da frequência escolar dos filhos e o comparecimento no posto de saúde. E, ao ingressar no mercado, Selma descobriu que os tempos para executar o trabalho também estavam na mira das tecnologias digitais.

A relação de Selma com a cultura digital, independentemente de ser considerada ou não incluída digitalmente, demonstra que o exercício da cidadania política e social é impactado com o alargamento proporcionado por softwares e pela internet, que viabiliza a articulação de vários órgãos e a sistematização de dados, possibilitando outras relações e tensionamentos em função da interação digital, que tanto intensifica as relações entre os cidadãos, o Estado e o mercado quanto traz outra dinâmica a elas (HADDAD, 2009). Portanto, a cultura digital não está restrita ao uso de determinados aparatos tecnológicos, mas deve ser compreendida como o sistema de valores, símbolos, práticas e atitudes que impacta tanto nas estruturas objetivas - acesso às políticas públicas, ao trabalho, à informação e a linguagens e códigos sociais - como na subjetividade dos sujeitos, sendo um instrumento de hierarquização social (MANEVY, 2009).

Amadeu (2009, p. 69) ajuda a ampliar a compreensão acerca desses impactos ao definir o digital como uma metalinguagem da cultura pós-industrial, que associada à internet possibilita a ampliação das relações interpessoais e o acesso à informação, entre outras ações, integrando-se de maneira significativa ao nosso ambiente cultural e estando presente em todas as atividades práticas contemporâneas. Nesse sentido podemos denominar cultura digital como uma "mescla de nosso modo de

1 São 50 milhões de brasileiros $25,4 \%$ da população, que vivem com renda familiar equivalente a R\$ 387,07 - (US\$ 5,5 por dia) - valor estipulado pelo Banco Mundial para definir a condição de pobreza (IBGE, 2017). 
pensar e agir, traduzida no que produzimos e atualizamos, a cibercultura", definição usada por Lèvy (1996) que, para Amadeu, pode ser entendida como sinônimo de cultura digital e representa o novo estágio da cultura de rede, um movimento histórico que marca a "conexão dialética" entre o sujeito humano e suas expressões tecnológicas, por meio da qual realizamos a transformação no mundo e nas nossas relações.

As questões abordadas por Selma e pontuadas pelos autores supracitados nos mostram a materialidade da reflexão de Lèvy (1996, p. 9) de que o real e o digital não são antônimos, mas se retroalimentam, pois o digital tanto é real como atualiza a realidade - inclusive, reatualiza valores e as estruturas de hierarquização das sociedades, em que há grupos que têm mais influência e poder para impor os caminhos, grupos esses que o autor denomina de coletivos mais virtualizados e virtualizantes. Portanto, como a nossa cultura contemporânea está associada às tecnologias digitais, criando uma nova relação entre a técnica e a vida social, ela afeta a todos, seja aqueles que têm o poder de elaborá-las, definir seus fins e rumos e comercializar esses bens - telefones celulares, computadores, notebooks, entre outros - seja os que são meros usuários ou aqueles que estão à margem, os vulneráveis sociais, que, às vezes, não têm acesso a alguns desses bens, mas sofrem o seu impacto nas suas vidas, como nos exemplificam os depoimentos de Selma.

\section{Cultura digital, inclusão e exclusão digital}

Pensar a inclusão digital e os seus impactos na contemporaneidade na perspectiva das parcelas que vivem esta dupla situação "incluído e excluído" requer compreender que o fluxo intenso de compartilhamentos de conteúdo, a mediação da comunicação por meio de artefatos tecnológicos e a alteração das dimensões do espaço-tempo, tornando-os mais dilatados, são ações sociais que vêm delineando e modificando a maneira como interagimos, ou seja, as práticas sociais. Constitui-se assim o que se denomina cultura digital, cujos significados e significações instituem, 
"organizam, codificam e regulam condutas em relação uns aos outros" (ALONSO, 2017, p. 27). Tal movimento tem nas mídias e no uso intensificado das Tecnologias Digitais da Informação e Comunicação (TDIC) instrumentos que potencializam a realidade virtual que, para Alonso (2017, p. 25), não se reduz às extensões do nosso corpo e nem a meras novas formas de expressões culturais, mas "são constitutivas de mudanças profundas nos modos pelos quais as culturas são organizadas". Trata-se de "processos vivos de articulação, processos políticos, sociais, que impactam nosso modo de vida, de construção e de formulação", no qual o digital não se restringe a um suporte, mas constitui-se em formas de elaborar e organizar, integrando-se ao funcionamento das instituições e espaços públicos e privados (MANEVY, 2009).

Se o virtual institui mudanças significativas na nossa cultura, não podemos perder de vista que há novas facetas de hierarquização social, novas formas de adjetivar as desigualdades - entre elas, os vulneráveis sociais que também podem receber a denominação de "cyber-analfabetos digitais", que estão à "margem": dentro dos sistemas de monitoramento e controle do Estado e do mercado, mas fora das posições de controle e produção desses bens materiais e imateriais; são os agentes passivos e impactados. Nessa direção, a compreensão da cultura digital requer alargar o olhar para além do aparato tecnológico e percebê-la enquanto um sistema que institui valores, símbolos, práticas e atitudes, que inclui cultura das redes, de compartilhamento, que pode possibilitar criação coletiva e convergência de interesses. Contexto que coloca a instituição escolar, que no decorrer da sua história tem se constituído como espaço de formação humana para a transmissão da cultura /conhecimento, à frente do desafio de problematizar a cultura digital nos processos educacionais. Se tivermos como referência as ações no âmbito da EJA, como é o caso do Mulheres Mil, um dos desafios, como nos provoca Buckingham (2010), que se interpõe a esse cenário é que o letramento verbal, compreendido aqui como a inserção na cultura escrita, não parece ser suficiente para inserir esses estudantes nos novos desígnios da cultura digital, numa sociedade cada 
vez mais dominada pela mídia eletrônica, - fato que requer pensar um currículo que incorpore o letramento digital.

Assim, para pensarmos o letramento digital, é importante discutir o que representa a inclusão digital. Silveira (2008) propõe que o entendimento desse conceito deve estar relacionado com o de exclusão digital, o que permitiria denunciar processos que impedem que a maioria da população possa utilizar as redes informacionais mediadas pelo computador. Perspectiva que alarga as reflexões de Lévy (1996), que trata o letramento digital como um demarcador temporal da inexistência de acesso para setores da população às novas tecnologias digitais, e pode restringir a inclusão digital ao mero ato de inclusão de consumidores a produtos hierarquizados por classe social, como vemos hoje na disputa comercial que se estabelece em torno dos celulares, por exemplo.

Nesse sentido, Martins (2009, p. 34) alerta que ao colocar o foco na exclusão corremos o risco de "deixarmos de discutir as formas pobres, insuficientes e, às vezes, até indecentes de inclusão", visto que que a exclusão digital não cria mais pobres, "cria uma sociedade paralela que é includente do ponto de vista econômico e excludente do ponto de vista social, moral e até político". Acrescentamos, a partir da realidade de Selma, que é includente para a inserção vigiada nas políticas gestão da pobreza públicas, mas excludente quando se trata de pensá-la com esses sujeitos.

Outro ponto relevante para refletir no contexto da escola é o fato, como ressalta Alonso (2017), de as TDIC viabilizarem uma dinâmica mais horizontal da produção da informação e de conteúdos, contando com ambientes virtuais nos quais as redes sociais constituem-se em "poderosos veículos" na criação/disseminação de informação e conteúdos, num contexto amplo de relações sociais que se opõe aos modos como a escola se organiza. A autora destaca ainda dois aspectos que são importantes nesse debate: a universalização do acesso às TDIC, tanto aos estudantes quanto à instituição escolar, e o estabelecimento das finalidades de seus usos. Buckingham (2010), por seu lado, aponta o desafio de compreender a necessidade dos múltiplos letramentos, demandados pelo conjunto de formas contemporâneas de comunicação. 
Diversos autores (ALONSO, 2017; BELLONI, 2012) apontam como questão chave na integração das TDIC na escola o seu papel no enfrentamento das desigualdades, por meio do acesso crítico à cultura digital, que, deste modo, se constitui em um processo mais amplo do que a disponibilidade de equipamento ou o desenvolvimento de habilidades e competências técnicas, mas requer também uma questão de capital cultural - a capacidade de usar formas culturais de expressão e comunicação (BUCKINGHAM, 2010).

As reflexões de Belloni (2012), mesmo que seus estudos tivessem como foco a televisão, contribuem para compreender as posições com as quais a escola se confronta e pode operar para garantir a inclusão digital. Uma delas é fortalecer o processo de reprodução acrítica, com foco meramente instrumental para que os alunos desenvolvam habilidades e competências, tendo os domínios necessários para ingressar no mercado de trabalho. A outra é propiciar caminhos para que estudantes e professores possam interagir com a cultura digital de forma crítica, podendo transformar-se em usuários criativos e críticos dessas novas ferramentas e assim assegurar que não se tornem meros consumidores compulsivos. Nessa segunda perspectiva, a autora propõe que os artefatos digitais sejam encarados enquanto ferramenta pedagógica para os processos de ensino e de aprendizagem, e como objeto de estudo complexo e multifacetado. Pensamos que também podem ser usados como instrumentos de combate às desigualdades sociais, articulando-se assim o direito de assegurar a inclusão de todos na sociedade do conhecimento, sem ampliar os processos de exclusão, via inclusão de estudantes das classes populares como consumidores passivos.

Trata-se na perspectiva de Warschauer (2006, p. 21) de um direito e, por isso, extrapola a visão de que o acesso pleno às TDIC se restrinja a poder usar computadores e internet, mas "requer recursos e relacionamento físicos, digitais, humanos e sociais”. Assim, inclusão digital precisa ser entendida como acesso reflexivo às novas tecnologias, seus conteúdos e linguagens e como ferramenta de luta contra a hierarquização educacional, social e econômica. 


\section{Da visibilidade ambígua da cultura digital: percurso teórico-metodológico}

Independentemente das posições sociais ocupadas, estamos todos imersos na cultura digital, cuja dinâmica está naturalizada a tal ponto que, muitas vezes, a vista do ponto a partir do qual enxergamos se estrutura na ambígua posição de in-visibilidade: indispensável na vida, mas ausente das reflexões sobre a micropolítica cotidiana. E o desvelamento desta posição ambígua se coloca na caminhada acadêmica desta pesquisa com e no Seminário Especial - Docência e a integração das tecnologias na educação, ministrada por Cerny e Espíndola, deslocando percepções acerca da cultura digital e da relação e posição dessas mulheres - as vulneráveis sociais - com as práticas sociais na "era digital" e dos significados da inclusão digital, compondo assim a trilha teórico-metodológica das reflexões apresentadas nesse texto.

Esse deslocamento possibilitou revisitar as entrevistas realizadas com mulheres-alunas e docentes, Selma e Leila Buarque ${ }^{2}$, que participaram da fase piloto da ação, de 2007 a 2010, nos seguintes materiais: livro Mulheres Mil: do sonho à realidade (ROSA, 2011b), e-book Mulheres Mil na Rede Federal: Caminhos da Inclusão (ROSA, 2011a), documentário Eu Tenho Um Sonho (RATTON,2009) e nos documentos oficiais do Programa. Nesses últimos, há ausência de expressões como cultura e inclusão digitais, mas tal inexistência é presentificada na disciplina de informática, central na formação profissional no Programa Mulheres Mil (BRASIL, 2011a; 2011b). Há, portanto, o reconhecimento de que os conteúdos relacionados às TDIC devem ser incorporados ao currículo para que essas mulheres possam ter acesso ao mundo de trabalho e assim fazer a transição da identidade de alunas vulneráveis sociais para a de trabalhadoras formais. Também reescavamos dados coletados e não publicados na pesquisa de mestrado, realizada de 2014 a 2016 (ROSA, 2016), entre os

2 Como os depoimentos dessas entrevistadas (Selma e Leila) estão publicados usamos os nomes reais; já os dos docentes e servidores que participaram da pesquisa de mestrado são fictícios. 
participantes do grupo focal, que contou com 15 pessoas, entre docentes e servidores do Instituto Federal de Santa Catarina (IFSC) e entrevista individual com representante do Centro de Referência da Assistência Social (CRAS). Nesse material, dando continuidade ao caminho investigativo iniciado no mestrado, cujo foco era compreender que saberes da experiência de vida das mulheres os docentes e servidores identificavam e reconheciam para a definição do curso (ROSA, 2016), buscamos identificar a presença da temática inclusão digital na fase piloto do Programa e na pesquisa de mestrado, com o objetivo de compreender as percepções dos docentes sobre a relação que as alunas do Mulheres Mil estabeleciam com a cultura digital e em que medida este olhar influenciava na abordagem do conteúdo de informática básica e aplicada que nas três qualificações ofertadas no IFSC - Zeladoria, Recicladora e Confeccionadora de Bijuteria - integrava o plano dos cursos com as seguintes nomeações e carga-horária: Tecnologias Digitais — Mulheres Mil (24h); Informática (10h); Informática (16h). No curso de camareira, ofertado pelo IFCE, optamos por analisá-los na perspectiva de Selma, para confrontar percepções de aluna e professor. Para a sistematização e análise dos dados, tomou-se como referência a análise de conteúdo temática e categorial (BARDIN, 2010), que permite focalizar a importância das palavras, do contexto e das circunstâncias nas quais a mensagem é vinculada.

\section{Entre o bicho-papão e o instrumento mágico: percepções dos docentes}

As percepções dos formadores acerca do conceito de vulnerabilidade social, além de aspectos retratados nos documentos oficiais pobreza, chefia familiar feminina (feminização da pobreza), violência doméstica, baixa escolaridade e desemprego (BRASIL, 2011a; 2011b), associa a esse marcador a vulnerabilidade psíquica (ROSA, 2016), como verificamos nestes depoimentos: 
A maioria das mulheres não têm profissão, escolaridade bem baixa. Eu acredito que tinha algumas que nem sabiam ler direito e escrever direito. A maioria, mães de vários filhos e pessoas da comunidade. Mulheres ociosas também, sem um afazer em casa, sem um objetivo na vida (ROSEMARY, Assistente Social do CRAS).

[Elas] são vítimas de violência, física ou psicológica. Muito forte as agressões. Elas contavam, elas procuravam [...] vinham machucadas, vinham escondido. Por isso que eu digo, tinha a agressão física em casa (SILVANA, gestora e professora do Programa Mulheres Mil no IFSC).

Nós aqui, as primeiras turmas do Mulheres Mil que recebemos, muito problema de depressão, é um perfil muito diferente. A depressão faz assim, ó: (gesticula com as mãos para mostrar um movimento ascendente e descendente, um sobe e desce). Depressão profunda, algumas saíam de atestado, entravam em clínica, sanatório, mesmo (SILVANA).

A realidade com a qual nos deparamos, de acordo com Pinzani e Rego (2014), pode ser analisada como uma das consequências das condições de pobreza. Além do aspecto material, a carência de recursos básicos para a sobrevivência, tais como alimentação, moradia, entre outros, afeta a subjetividade, causando sofrimento. Portanto, deveria ser configurada como patologia social, mas acaba sendo tratada no âmbito individual, muitas vezes com a medicalização, repercutindo na autoculpabilização. No entanto, inferimos que por se tratar de um fenômeno que a escola desconhece e que a sociedade tende a interpretar como uma "característica" individual, no âmbito do programa o "quadro de depressão" é interpretado como uma situação que necessita de certa flexibilização na relação entre docente e aluno e no processo ensino-aprendizagem. Situação que requer "cuidado" e "paciência" do professor, como podemos detectar nessa indicação de Silvana:

Um desafio que nós comentávamos no início: olha o perfil, cuidado, avisa, conversa com a psicóloga, nos chama, porque não pode entrar assim em conflito, tem que aceitar, levar para o CRAS, para a nossa psicóloga, para resolver. Então, quando o professor for dá aula assim: bem tranquilo, 
bem light, sem chamar a atenção, uma está deitada, dormindo, a outra não está fazendo nada, é o perfil, não tem obrigação (SILVANA).

Este depoimento de Silvana desloca o debate para analisar essa questão a partir dos comportamentos das alunas na sala de aula, momento em que um dos professores da disciplina de informática no IFSC, Rodrigues, associa o computador a poderes mágicos de acalmá-las. Vejamos:

Na minha aula, elas apresentavam ser mais tranquilas, que eu acho que era uma aula que chamava a atenção delas, que elas ficavam mais entretidas, né? Não ficavam com a preocupação das coisas que aconteciam lá fora. [...] elas ficavam tão concentradas na frente do computador que elas esqueciam o que tinha na rua (RODRIGUES, professor de Informática, IFSC).

Você tinha a pecinha mágica? (Risos) (Pesquisadora).

Eu tinha a pecinha mágica. Elas ficavam concentradas ali, lá fora para elas nem existia. Elas ficavam ali tão concentradas que quando eu dizia acabou a aula, diziam: ah, passou a hora? Já está na hora de ir embora? (RODRIGUES, professor de Informática, IFSC).

Aqui podemos identificar um ponto de intersecção diametralmente oposto entre a percepção de Selma, para quem a dupla computador e internet era um bicho-papão, e a de Rodrigues, que a simboliza como "instrumentos mágicos" "calmantes tecnológicos", tão fascinantes para as mulheres que conseguiam suspender, temporariamente, comportamentos "depressivos". O depoimento de Lúcia coaduna-se com essa visão, ao pontuar que o interesse das alunas pelo computador sobrepunha-se aos das demais disciplinas: "[...] elas queriam usar o computador, não queriam matemática, saúde da mulher, elas não queriam fazer as outras (disciplinas), queriam o computador".

Ora, esses depoimentos suscitam a questão levantada por Martins (2009) ao alertar que o foco na exclusão pode invisibilizar as formas marginais como essas mulheres já se encontram na cultura digital, reduzindo a concepção de inclusão digital ao uso do computador e da 
internet, sem perceber que, mesmo que muitas estudantes do Mulheres Mil sejam neófitas no manejo com computador e internet, elas têm familiaridade com outras tecnologias, como o celular, principal instrumento de contato entre elas e os agentes das políticas públicas (CRAS e gestores do Mulheres Mil); o cartão do banco com o qual sacam o recurso do Bolsa Família e o processo de monitoramento das exigências das políticas públicas de combate à pobreza que, por meio do NIS, ligam a beneficiária aos sistemas de saúde e educação e por meio dos dados de frequência definem sua continuidade ou não nas políticas. Inferimos assim que o fato de os professores não identificarem a existência de relações das mulheres com as TDIC parece trazer uma dinâmica de retroalimentação entre o medo que elas demonstram do bicho-papão e as pecinhas mágicas, como denomina Rodrigues, correndo o risco de reduzir a inclusão digital ao repasse instrumental de conteúdos básicos, expresso nessas falas.

[...] eu fui trabalhando com elas, deixando elas mais livres, trabalhando devagarinho, vendo os interesses delas, o que que elas queriam ver na internet $[. .$.$] com as áreas que elas gostavam. Aí umas iam lá pro-$ curar negócio de tricô, outras iam lá procurar o negócio de artesanato, outras iam procurar negócio de culinária, não sei o quê, então foi uma experiência boa (RODRIGUES, professor de Informática, IFSC).

Isso me impressionou bastante. Era como se fosse um prêmio elas poderem entrar na internet, poderem acessar sites, coisas que muitas de nós fazem corriqueiramente. Já, para elas, era tudo novo, poder visitar e conhecer esse novo mundo e aquela máquina. [...] Apesar de a carga horária ser pequena, eu acho que consegui despertar nas que não tinham conhecimento nenhum que elas podem sim, independentemente de terem feito algum curso, sentar numa lan house, poder ter e-mail, se comunicar com o mundo (Leila Buarque, professora de informática do IFSC) (ROSA, 2011a).

Reduzir a inclusão digital ao mero uso de computador, internet e mouse ou à habilidade de abrir um e-mail, como retratam esses depoimentos, não garante a interação dessas mulheres enquanto usuárias críticas da 
tecnologia digital, como ressaltam Buckingham (2010) e Belloni (2012). Selma, a nossa camareira de sucesso, compreende que o computador permite o monitoramento dos seus tempos de trabalho, o que a leva a se autodisciplinar e autovigiar para atender às exigências e com isso garantir a permanência no mercado de trabalho, o que não significa que ela perceba que os códigos e linguagens usados nesses aparatos podem possibilitar outros meios de sua inserção no mundo do trabalho: a organização de cooperativa, por exemplo, por meio da qual poderia ofertar seu trabalho. Considerando as situações de violência doméstica que muitas enfrentam, também é possível pensar de que forma o fluxo intenso de comunicação permite a criação de redes nas quais essas mulheres poderiam encontrar formas de atuação política - denúncia e prevenção para combater essa violência e pressionar uma outra relação com o Estado, com ações mais efetivas, como ressaltam Haddad (2009) e Manevy (2009).

Superar o medo do computador, certamente, foi fundamental para Selma lidar com as exigências que a tecnologia digital integrou ao trabalho de camareira, não mais reduzível à habilidade de limpar o quarto dentro dos padrões exigidos, sendo necessário o mínimo de conhecimento com a linguagem digital. Assim, se, por um lado, há necessidade de estabelecer uma relação instrumental com os conteúdos da informática no processo educacional, imprescindíveis para que essas mulheres-estudantes ingressem no mercado de trabalho, como relata Selma, quando conta que o botão "clean" representa o código a ser digitado - sinal que o quarto está limpo - e a partir do qual se mede e automede a produtividade do corpo da camareira, por outro lado, incluí-las com a intenção de adequá-las aos novos ditames do processo civilizatório da pós-modernidade, ao convívio social, como ressalta Leila, também reduz o processo de inclusão digital à subalternidade, à continuidade e manutenção da hierarquização social da Ralé (SOUZA, 2009).

Para mim, o que ficou de bom foi ver que elas conseguiram pegar o mínimo. A importância da inclusão digital é que quando você inclui não é só numa caixinha chamada computador. Você tá incluindo no 
convívio social: ir a um banco tirar um extrato, entrar na Internet, enfim, lidar com novas tecnologias, inclusive o celular, onde elas podem passar mensagem, por exemplo (ROSA, 2011a).

Cupani (2017), ao abordar a tecnologia na perspectiva filosófica, ajuda a pensar que ela faz parte da produção material dos homens e mulheres e retrata um saber específico ante uma realidade, e o desafio da escola é não resumir o seu olhar à tecnologia digital, mas alargá-lo para identificar que aqueles que estão em condições de vulnerabilidade social são potenciais produtores de tecnologia que podem ser elaboradas a partir das suas condições de existência.

\section{Considerações finais}

Neste artigo tivemos o desafio de discutir a inclusão digital, por meio de processos formativos para mulheres em situação de vulnerabilidade social, alvo das políticas sociais de combate à pobreza. O estudo analisou as percepções de docentes e servidores do Programa Mulheres Mil sobre a relação dessas mulheres com a cultura digital. Para análise, dialogamos com as teorias que tecem os cruzamentos entre os campos da Educação e da Comunicação, procurando ultrapassar os conceitos de exclusão social e inclusão digital e compreender a inclusão/exclusão a partir do conceito de vulnerabilidade social. Problematizamos a ambiguidade presente nas discussões sobre a integração e a percepção das relações dessas pessoas na e com a cultura digital.

Identificamos um ponto de intersecção diametralmente oposto entre a percepção das mulheres em formação, para quem a dupla computador e a internet era um bicho-papão, e a dos formadores, que a simboliza como "instrumentos mágicos", "tranquilizantes tecnológicos" que as faziam se concentrar nas tarefas de tal forma que suspendiam, temporariamente, comportamentos "depressivos". No entanto, os formadores não ultrapassam o ensino instrumental das tecnologias, obnubilando a necessária formação crítica desses sujeitos e consequentemente 
as possibilidades de outros meios de sua inserção política, econômica e social, com outras formas de organizar e se inserir no mercado de trabalho, seja por meio de cooperativas, associações ou quem sabe inventar outras formas solidárias e formas mais diretas e efetiva de participação na elaboração de políticas de combate à pobreza e à violência doméstica. Ao contrário dos formadores, as mulheres percebem o controle que a tecnologia exerce sobre suas vidas.

\section{Referências}

ALONSO, K. M. Cultura digital e formação: entre um devir e realidades pungentes. In: CERNY, R. Z. et al. (Org.). Formação de Educadores na Cultura Digital: a construção coletiva de uma proposta. Florianópolis: UFSC/CED/NUP, 2017. p. 23-39.

AMADEU, S. Economia da Cultura Digital. In: SAVAZONI, R.; COHN, S. (Org.). Cultura digital.br. Rio de Janeiro: Beco do Azougue, 2009. p. 67-77.

BARDIN, L. Análise de Conteúdo. 5. ed. São Paulo: Edições Loyola, 2010. 280 p.

BELLONI, M. L. Mídia-Educação: Contextos, Histórias e Educação. In: FANTIM, M.; RIVOLTELIA, P. C. (Orgs.). Cultura Digital e Escola: pesquisa e formação de professores. Campinas: Papirus, 2012.

BONILLA, M. H. S.; OLIVEIRA, P. C. S. Inclusão Digital: Ambiguidades em curso. In: BONILLA, M. H. S.; PRETTO, N. D. L. (Orgs.). Inclusão digital: polêmica contemporânea. Salvador: EDUFBA, 2011. p. 23-48.

BUCKINGHAM, D. Cultura Digital, Educação Midiática e o Lugar da Escolarização. Educ. Real., Porto Alegre, v. 35, n. 3, p. 37-58, set./dez. 2010.

BRASIL. Lei n ${ }^{\circ}$ 10.836, de 9 de janeiro de 2004. Cria o Programa Bolsa Família, e dá outras providências. Brasília, 2004. Disponível em: < http://www.planalto.gov.br/ ccivil_03/_Ato2004-2006/2004/Lei/L10.836.htm>. Acesso em: 10 ago.2018 
BRASIL. Ministério da Educação. Programa Nacional Mulheres Mil: Educação, Cidadania e Desenvolvimento Sustentável. Brasília, 2011a. Disponível em: <http:// portal.mec.gov.br/programa-mulheres-mil/publicacoes >. Acesso em: 12 ago. 2018.

BRASIL. Ministério da Educação. Guia Metodológico do Sistema de Acesso, Permanência e Êxito. Brasília, 2011b. Disponível em: <http://portal.mec.gov.br/ programa-mulheres-mil/publicacoes $>$. Acesso em: 12 ago. 2018.

CHANT, S. Re-thinking the "feminization of poverty" in relation to aggregate gender indices. Journal of Human Development, v. 7, n. 2, p. 1-20, 2006.

CUPANI, A. Filosofia da Tecnologia: um convite. 3. ed. Florianópolis: Ed. UFSC, 2017. 234 p.

EUTENHOUMSONHO. Direção:Helvécio Ratton. [S.1.]: Mulheres Mil, 2009. Youtube (26 min). Disponível em: 〈https://www.youtube.com/watch?v=reJN2hiAVmE〉. Acesso em: 10 ago. 2018

HADDAD, F. Política da Cultura Digital. In: SAVAZONI R; COHN, S. (Orgs.). Cultura digital.br. Rio de Janeiro: Beco do Azougue, 2009. 312 p.

INSTITUTO BRASILEIRO DE GEOGRAFIA E ESTATÍSTICA (IBGE). Censo 2017. Brasília: IBGE, 2017. Disponível em: <https://www.ibge.gov.br/estatisticas-novoportal/sociais/populacao.html >. Acesso em: 12 ago. 2018.

LÈVY, P. O que é cibercultura. São Paulo: Editora 34, 1996. 164 p.

MONTEIRO, S. R. R. P. O marco conceitual da vulnerabilidade social. Sociedade em Debate, Pelotas, v. 17, n. 2, p. 29-40, jul./dez. 2011.

MANEVY, A. Política da Cultura Digital. In: SAVAZONI, R.; COHN, S. (Orgs.) Cultura digital.br. Rio de Janeiro: Beco do Azougue, 2009. 312 p.

MARTINS, J. S. Exclusão social e nova desigualdade. 4. ed. São Paulo: Paulus, 2009. PINZANI, A.; REGO, W. L. Vozes do Bolsa Família: autonomia, dinheiro e cidadania. 2. ed. São Paulo: Unesp, 2014. 249 p. 
ROSA, S. Mulheres Mil na rede federal: caminhos da inclusão. Brasília: MEC, 2011a. 168 p. (E-book). Disponível em: <http://mulheresmil.mec.gov.br/images/stories/pdf/geral/mulheres_mil_na_rede_federal_-_caminhos_da_inclusao. pdf >.Acesso em: 12 ago. 2018

ROSA, S. Mulheres Mil: do sonho à realidade. Brasília: MEC, 2011b. 145 p. Disponível em: <http://mulheresmil.mec.gov.br/central-de-entrevistas/1676-mulheres-mil-do-sonho-a-realidade>. Acesso em: 12 ago.2018

ROSA, S. Reconhecimento de saberes no Programa Mulheres Mil: entre a colonialidade do poder e de gênero. 2016. 287 p. Dissertação (Mestrado em Educação) - Universidade Federal de Santa Catarina, Centro de Ciências da Educação, Programa de Pós-Graduação em Educação, Florianópolis, 2016.

SOUZA, J. Ralé Brasileira: quem é e como vive. Belo Horizonte: Editora UFMG, 2009. $484 \mathrm{p}$.

SILVEIRA, S. A. A noção de exclusão digital diante das exigências de uma cibercidadania. In: HETKOWSKI, T. M. (Org.). Políticas públicas \& inclusão digital. Salvador: EDUFBA, 2008.

WARSCHAUER, M. Tecnologia e inclusão social: a exclusão digital em debate. Trad: Carlos Szlak. São Paulo: Editora Senac. 2006.

Recebido: 31/07/2018

Received: 07/31/2018

Aprovado: 10/09/2018 Approved: 09/10/2018 